\title{
BMJ Open Delayed healthcare seeking and prolonged illness in healthcare workers during the COVID-19 pandemic: a single-centre observational study
}

\author{
Angus de Wilton (D) , ${ }^{1}$ Eliz Kilich, ${ }^{1}$ Zain Chaudhry, ${ }^{1}$ Lucy CK Bell, ${ }^{1}$ Joshua Gahir, ${ }^{1}$ \\ Jane Cadman, ${ }^{2}$ Robert A Lever, ${ }^{1,3}$ Sarah A Logan, ${ }^{1}$ On behalf of UCLH COVID-19 \\ Response Team
}

To cite: de Wilton A, Kilich $E$, Chaudhry Z, et al. Delayed healthcare seeking and prolonged illness in healthcare workers during the COVID-19 pandemic: a single-centre observational study. BMJ Open 2020;10:e040216. doi:10.1136/ bmjopen-2020-040216

- Prepublication history and additional material for this paper are available online. To view these files, please visit the journal online (http://dx.doi org/10.1136/bmjopen-2020040216).

EK, ZC, LCB and JG contributed equally.

Received 08 May 2020 Revised 19 0ctober 2020 Accepted 14 November 2020

Check for updates

(C) Author(s) (or their employer(s)) 2020. Re-use permitted under CC BY-NC. No commercial re-use. See rights and permissions. Published by BMJ.

For numbered affiliations see end of article.

Correspondence to Dr Angus de Wilton; angus.dewilton@nhs.net

\section{ABSTRACT}

Objectives To describe a cohort of self-isolating healthcare workers (HCWs) with presumed COVID-19.

Design A cross-sectional, single-centre study.

Setting A large, teaching hospital based in Central London with tertiary infection services.

Participants 236 HCWs completed a survey distributed by internal staff email bulletin. 167 were women and 65 men.

Measures Information on symptomatology, exposures and health-seeking behaviour were collected from participants by self-report.

Results The 236 respondents reported illness compatible with COVID-19 and there was an increase in illness reporting during March 2020 Diagnostic swabs were not routinely performed. Cough $(n=179,75.8 \%)$, fever $(n=138$, $58.5 \%)$, breathlessness $(n=84,35.6 \%)$ were reported. Anosmia was reported in $42.2 \%$. Fever generally settled within 1 week ( $n=110 / 138,88 \%$ ). Several respondents remained at home and did not seek formal medical attention despite reporting severe breathlessness and measuring hypoxia ( $n=5 / 9,55.6 \%)$. 2 patients required hospital admission but recovered following oxygen therapy. 84 respondents $(41.2 \%)$ required greater than the obligated 7 days off work and 9 required greater than 3 weeks off.

Conclusion There was a significant increase in staff reporting illness compatible with possible COVID-19 during March 2020. Subsequent serology studies at the same hospital study site have confirmed sero-positivity for COVID-19 up to $45 \%$ by the end of April 2020 in frontline HCWs. The study revealed a concerning lack of healthcare seeking in respondents with significant red flag symptoms (severe breathlessness, hypoxia). This study also highlighted anosmia as a key symptom of COVID-19 early in the pandemic, prior to this symptom being more widely recognised as a feature of COVID-19.

\section{BACKGROUND}

In response to the COVID-19 pandemic, the UK government enacted a range of policies to limit the spread of infection. These included guidelines on self-isolation for symptomatic individuals and a formal social distancing policy. ${ }^{1}$
Strengths and limitations of this study

- This study describes a large cohort of self-reported healthcare worker (HCW) COVID-19 illness during the peak of the COVID-19 pandemic in London.

- Study respondents represented a broad range of job roles, including both frontline clinical and nonpatient facing staff in a hospital setting proven to have a high incidence of COVID-19 infection during the study period.

- The inclusion of questions focusing on healthseeking behaviour allows results to be used to inform human resource management in the developing pandemic, and provides concerning but important data around late healthcare seeking in HCWs.

- Limitations include the use of a self-reported, crosssectional and retrospective survey, which may be subject to recall bias.

- Survey questions, testing and recommendations during the study were consistent with (and constrained by) early pandemic UK government recommendations at the time, and therefore may not accurately reflect what is now known about COVID 19.

Healthcare workers (HCWs) are at a disproportionate risk for COVID-19 disease through occupational exposure. ${ }^{2}$ Additionally, there are emerging concerns that HCWs may be at an additional risk of developing severe disease through repeated exposure to high viral loads in the clinical environment. ${ }^{3}$ This has implications for workforce planning and operational preparedness in the current crisis.

At the time of the study, SARS-CoV-2 testing was not routinely available for UK HCWs. Instead, HCWs fitting the Public health England (PHE) case definition for COVID-19 infection (persistent cough, fever) were advised to self-isolate for a minimum of 7 days from the onset of symptoms and return 
to work after this period if symptoms free. ${ }^{4}$ Governmental websites advised seeking formal medical attention only if difficulty breathing developed; this was later updated to any deterioration or failure to improve. ${ }^{5}$ Avenues of medical advice open to patients in the UK include NHS 111, a free online and telephone triage and advice system; the patient's own general practitioner (GP) and Accident and Emergency (A\&E) departments in secondary care. These resources are in addition to informal health advice provided by friends, family or colleagues. Little is currently described about healthcare-seeking behaviour in HCWs during the COVID-19 pandemic.

Several symptoms have been described in individuals with suspected and confirmed COVID-19, including fever, cough and shortness of breath ${ }^{67}$ and anosmia, with few detailed studies looking specifically at HCW illness, ${ }^{8}$ and none specifically focusing on healthcare seeking in this cohort.

In this study, we describe the experiences and symptoms of HCWs self-isolating for presumed COVID-19 infection in a cohort of frontline HCWs in a central London teaching hospital known to have very high levels of staff COVID-19 infection. ${ }^{2}$ We aim to examine the healthcareseeking behaviours in this unique cohort.

\section{METHODS}

We performed a cross-sectional, single-centre study of NHS HCWs who self-isolated with symptoms compatible with COVID-19 during the early COVID-19 pandemic. The study was designed as a survey-based cross-sectional study of HCWs unwell early in the pandemic. The study setting was University College London Hospitals NHS Foundation Trust. Eligibility criteria were: current employment at University College London Hospitals NHS Foundation Trust, and haven undertaken self-isolation since 1 March with either a fever or persistent cough as per the PHE guidelines for HCWs. Participants were recruited via staff email bulletin to all staff departments. Patients and public were not recruited to the study. Participants were asked to report potential exposures to COVID-19, access to personal protective equipment (PPE), variety and duration of symptoms, occupational health data and healthcare-seeking behaviours. Data sources were by selfreported survey (online supplemental file) and the study did not obtain access to medical records of participants. The study size was determined by the number of respondents during the survey window, with reminder emails sent regularly. The study team attempted to reduce selection bias by circulating the email survey to as many departments as possible, and attempting to recruit from both clinical and non-clinical settings. The survey was open between 1 April and 10 April 2020. Consent was obtained via electronic signature. Responses were devoid of personal identifiers and were collected and processed via Form Assembly Enterprise cloud (https://www.formassembly.com/). All data were stored in compliance with the General Data Protection Regulation (EU GDPR 2016/679) and Data Protection Act (UK 2018). The study
Table 1 Demographics of respondents

\begin{tabular}{|c|c|}
\hline Demographic & $\mathrm{n}=236(\%)$ \\
\hline \multicolumn{2}{|l|}{ Sex } \\
\hline Female & 167 (70.8) \\
\hline \multicolumn{2}{|l|}{ Age (years) } \\
\hline $18-28$ & $53(22.5)$ \\
\hline $29-39$ & 88 (37.3) \\
\hline $40-50$ & $66(28.0)$ \\
\hline $50-60$ & $21(8.9)$ \\
\hline $61-71$ & $3(1.3)$ \\
\hline \multicolumn{2}{|l|}{ Workplace } \\
\hline $\mathrm{UCH}$ & $229(97.0)$ \\
\hline Other & $4(1.7)$ \\
\hline Hospital & $228(96.6)$ \\
\hline Community & $5(2.1)$ \\
\hline \multicolumn{2}{|l|}{ Job role } \\
\hline Doctor & 79 (33.5) \\
\hline Nurse & $60(25.4)$ \\
\hline Administrator & $18(7.6)$ \\
\hline Other & $17(7.2)$ \\
\hline Other allied healthcare professional & $17(7.2)$ \\
\hline Radiographer & $14(5.9)$ \\
\hline Manager & $9(3.8)$ \\
\hline Healthcare assistant & $8(3.4)$ \\
\hline Physiotherapist & $6(2.5)$ \\
\hline Dietician & $4(1.7)$ \\
\hline Other non-clinical support & $2(0.8)$ \\
\hline Occupational therapist & $1(0.4)$ \\
\hline \multicolumn{2}{|l|}{ Smoking status } \\
\hline Smoker & $8(3.4)$ \\
\hline Non-smoker & $188(79.7)$ \\
\hline Ex-smoker & $32(13.6)$ \\
\hline \multicolumn{2}{|l|}{ Vulnerable group* } \\
\hline Yes & $24(10.2)$ \\
\hline
\end{tabular}

Demographic data collected via survey from staff at University College Hospital London.

*As defined by Public Health England (https://www.gov.uk/ government/publications/covid-19-guidance-on-social-distancingand-for-vulnerable-people/).

$\mathrm{UCH}$, University College Hospital.

was approved by the Audit and Research Committee at the Hospital of Tropical Diseases, UCLH. ${ }^{10}$ Anonymous data were exported to Microsoft Excel 2010 (Microsoft Corporation) and R (R Development Core Team 2008) for analysis. $\chi^{2}$ univariate analyses were performed using $\mathrm{R}$ to determine association between patient factors and duration of time off work, and healthcare-seeking behaviour. The majority of data were presented in a descriptive fashion. Venn diagrams were generated using 
Venny V.2.1.0 (https://bioinfogp.cnb.csic.es/tools/ venny/) ${ }^{11}$ and BioVenn (https://www.biovenn.nl/) ${ }^{12}$ to describe overlap of symptom clusters.

\section{Patient and public involvement}

This study involved NHS staff members only and did not recruit from the general public or NHS patient population. Results will be disseminated to staff via email bulletin.

\section{RESULTS}

\section{Demographics, timeline and exposure history}

During the study period, 984 staff were recorded as being off work with confirmed or possible COVID-19 at the study site, of which 236 responded to our survey. Of the 236 respondents to the survey $167(70.8 \%)$ were women and $27.5 \%$ men (table 1). Respondents were aged between 18 and 71 years. The respondents were from a broad range of hospital roles with the most common groups being doctors $(33.5 \%)$ and nurses $(25.4 \%)$. There was a broad range of other professions represented. The majority were non-smokers $(79.7 \%)$, with $32(13.6 \%)$ ex-smokers and 8 current smokers $(3.4 \%)$. Twenty-four respondents $(10.2 \%)$ reported being in a vulnerable group according to PHE criteria. ${ }^{1}$

Known direct contact with SARS-CoV-2 positive patients was reported in 81 HCWs (34.3\%) (figure 1A), of which $24(29.1 \%)$ of these were in appropriate personal protective equipment as perceived by respondents. Over half of those surveyed (128 respondents, 53.4\%) were not aware of having had any direct contact with COVID-19 positive patients. Initial suspected cases were identified in midFebruary and increased until late March 2020 (figure 1B).

Respondents were asked to report symptoms they experienced while unwell with an illness they perceived to be COVID-19. The number of respondents reporting each symptom is shown in table 2. The most reported symptoms included headache $(78.8 \%)$, cough $(75.8 \%)$, myalgia $(63.6 \%)$ and fever $(58.5 \%)$ (table 2). Eightyfour respondents $(35.6 \%)$ reported dyspnoea during their illness; of these 41 patients $(17.4 \%)$ reported shortness of breath only on exertion. Twelve patients $(5.1 \%)$ reporting shortness of breath at rest. Nearly one-third of HCWs experienced symptoms beyond 14 days (73 respondents, $30.9 \%$ ).

\section{Healthcare-seeking behaviour in HCWs}

The most commonly reported mode of healthcare seeking during illness was informal advice (26.7\%), NHS $111(25.4 \%)$ and general practice $(7.6 \%)$. Two patients attended A\&E and required oxygen therapy during hospital admission.

A minority of respondents had access to monitoring of oxygen saturations during their illness, and of those who commented on saturation levels, $11(4.7 \%)$ described saturations below $94 \%$ during their illness. Two respondents reported saturations below $85 \%$ either at rest or exertion. Only $41.7 \%$ of those with breathlessness at rest
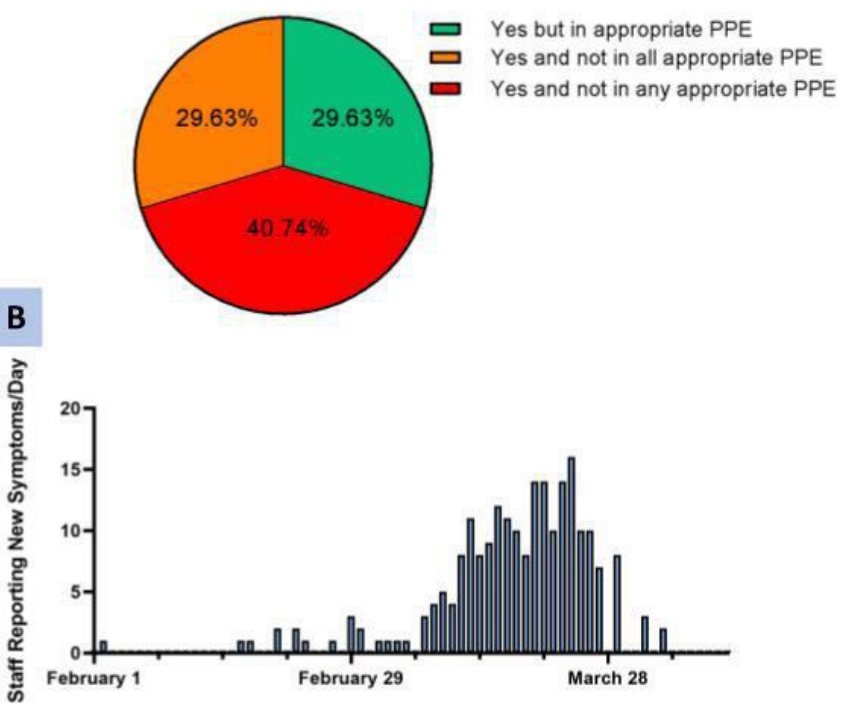

Figure 1 Self-perceived PPE usage and date of symptom onset in healthcare workers. (A) Eighty-one of 236 respondents reported an exposure to a patient who was confirmed or subsequently confirmed to be SARS-CoV-2 positive. The pie chart shows the breakdown of responses in this group when asked whether they considered that they were wearing appropriate PPE, partly appropriate PPE or no appropriate PPE at the time of this exposure. $40.74 \%$ of respondents in this group ( $n=33,13.98 \%$ of overall cohort) reported they considered that they were not wearing any appropriate PPE at the time of exposure. (B) Respondents were asked to report their first day of symptom onset. most reported symptom onset occurring within the first 3 weeks of March 2020. HCWs, healthcare workers; PPE, personal protective equipment.

$(n=12)$ and $44.2 \%$ of those who were breathless on exertion $(n=43)$, sought formal medical advice (figure 2A). Notably, nine respondents reported a combination of breathlessness and saturations less than $94 \%$ at rest; of these respondents half did not seek any formal healthcare advice (figure 2B).

$\chi^{2}$ univariate analysis was performed to determine associations between symptoms and demographics and healthcare-seeking behaviour. Formal healthcare seeking was defined as seeking assistance from NHS 111, GP or A\&E services. Respondents reporting shortness of breath were significantly more likely to seek formal healthcare $(p=0.008)$, while those reporting fever $(p=0.614)$, cough $(p=0.211)$ and chest pain $(p=0.132)$ did not have increased rates of healthcare seeking. Age $>50$ years $(p=0.773)$ and sex $(0.394)$ were not associated with rates of healthcare seeking.

The most common medications taken during selfisolation are described in online supplemental table 1.

\section{Self-isolation and return to work}

The majority of respondents $(57.3 \%)$ did not feel able to effectively distance themselves from household members while unwell (as defined as access to a separate bedroom 
Table 2 Retrospective recall of symptoms during illness

\begin{tabular}{lc}
\hline Symptom during self-isolation & $\mathbf{n = 2 3 6}(\%)$ \\
\hline Headache & $186(78.8)$ \\
Cough & $179(75.8)$ \\
Arthralgia/myalgia & $150(63.6)$ \\
\hline Fever/chills & $138(58.5)$ \\
\hline Pharyngitis & $134(56.8)$ \\
Coryzal symptoms & $117(49.6)$ \\
Sleep disturbance & $99(41.9)$ \\
Anosmia & $97(41.1)$ \\
Shortness of breath & $84(35.6)$ \\
Diarrhoea & $75(31.8)$ \\
Anxiety & $72(30.5)$ \\
Chest pain & $65(27.5)$ \\
Rash & $13(5.5)$ \\
Vomiting & $10(4.2)$ \\
\hline
\end{tabular}

and/or toilet) (figure 2C). Close contacts (defined as sharing a bed with symptomatic respondent on night prior to symptom onset) frequently became unwell during the 14 days after symptom onset of respondents (figure 2C). Time to return to work varied in this cohort, with a significant number of respondents requiring greater than 7 days off work prior to return (figure 2D). Nine respondents required greater than 3 weeks off work $(4.4 \%)$. In addition, $20 \%$ of respondents felt they returned to work before they felt ready.

Univariate $\chi^{2}$ analyses were performed to determine association between symptoms and demographic factors and requirement to take $>7$ days off work. There was not association between age $(\mathrm{p}=0.562)$ and/or gender (0.397) and absence from work beyond 7 days. Those reporting cough were significantly more likely to remain off work after 7 days $(\mathrm{p}=0.018)$, while there was a nonsignificant trend towards respondents with shortness of breath $(\mathrm{p}=0.07)$ requiring greater than 7 days off work.

\section{Persistent symptoms and neurological symptoms}

Fever persisted beyond 7 days in 15 respondents (figure 3A). Almost all respondents reported headache, cough and/or myalgia) with only nine individuals (3.8\%) not reporting one of these symptoms

A variety of neurological syndromes have been linked to COVID-19; in particular anosmia. ${ }^{13}$ Ninety-one respondents described anosmia during their illness (41.1\%) and 13 reported anosmia prior to isolating guided by the PHE guidance at the time, which excluded anosmia as a symptom of COVID-19 (7.0\%). Most individuals with anosmia also reported headache (figure 3B). Onset of anosmia peaked at days 3-4 of illness with $84 \%$ reporting symptomatic resolution within 14 days (figure $3 \mathrm{C}$ ).

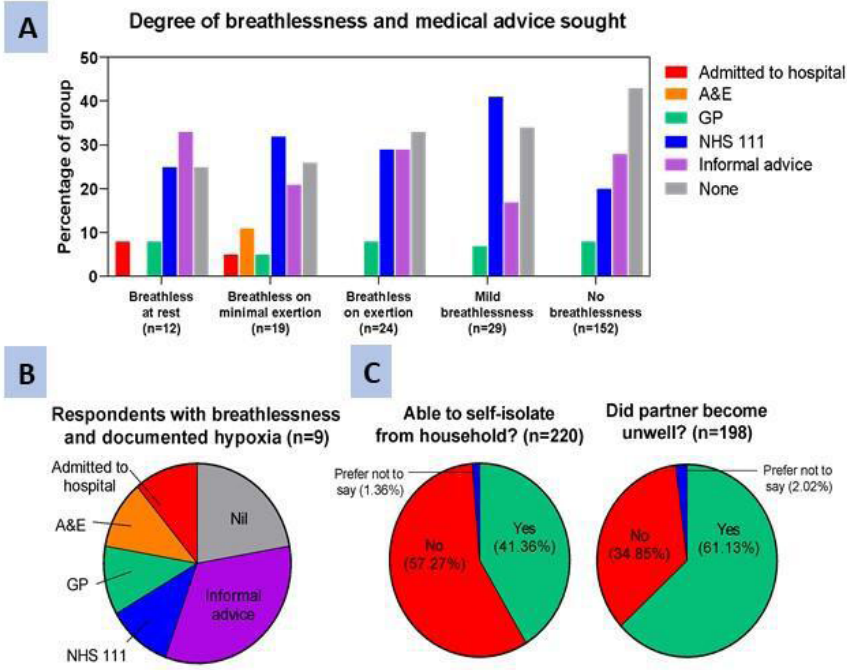

D

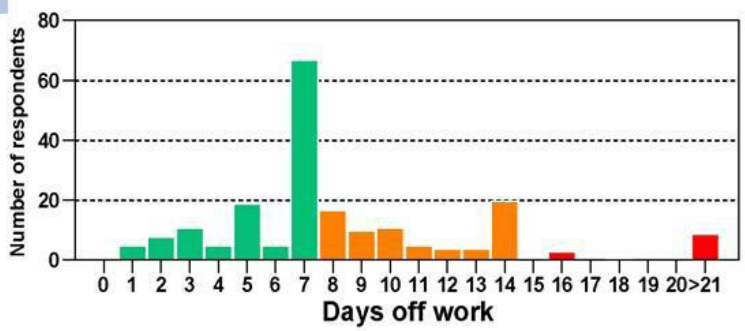

Figure 2 Healthcare-seeking behaviour as triggered by breathlessness in HCWs $(A)$; access to self-isolation facilities (B); illness in close contacts of HCWs (C); return to work timeline (D). (A) Eighty-four respondents reported breathlessness (35.6\%); increased severity of breathless did not appear to lead to increased formal healthcare seeking in respondents. Of those respondents reporting breathlessness at rest $(n=12)$, only $41.7 \%(n=5 / 12)$, sought formal medical attention (NHS 111, GP, A\&E). (B) Nine respondents reported a combination of breathlessness and saturations of $<94 \%$ (measured using home oximeters). A majority $(n=5 / 9)$ of those respondents sought either no or informal advice only. (C) Respondents were asked if they felt able to self-isolate away from other household members (separate bedroom, bathroom). A majority did not feel able to self-isolate in this way $(n=126,57.27 \%)$. (D) Respondents were asked whether their partner became unwell (phrased as 'sharing bed on night of symptom onset') during 14 days after symptom onset. A majority ( $n=125,61.13 \%)$ reported their partners did become unwell during this period. A\&E, Accident and Emergency; GP, general practitioner; HCWs, healthcare workers.

\section{DISCUSSION}

This study collected early data on HCW illness during the peak of the COVID-19 pandemic at a major London teaching hospital. During the study period, 984 staff were off work with possible or confirmed COVID-19, and we describe 236 of these HCWs in this study. This study was unique in capturing data on healthcare-seeking behaviour, self-isolation facilities and return to work timelines of HCWs with presumed COVID-19 early in the UK Pandemic. 


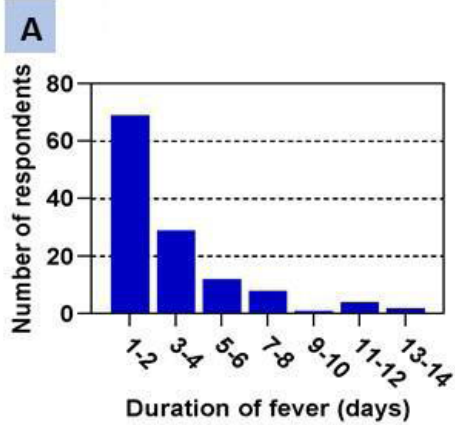

B
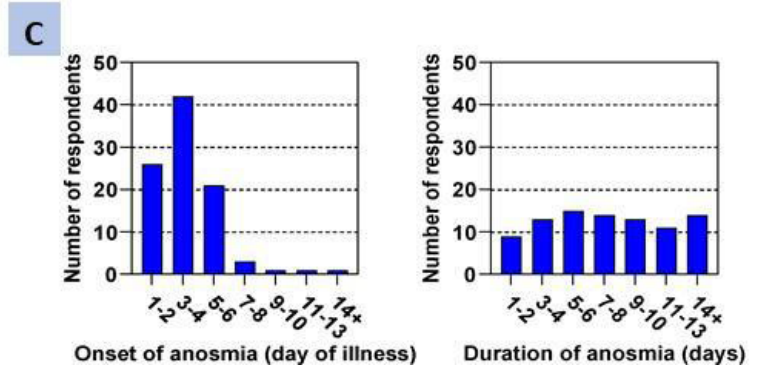

Figure 3 Duration of reported fever in self-isolating healthcare workers (A); clustering of headache and anosmia (B) and characterisation of anosmia (C). (A) respondents were asked to report the duration of their fever. The majority of respondents reported fever duration less than 7 days $(n=110,88)$. fever persisted to 7 days or more in $12 \%$ $(n=15)$. (B) Proportional Venn diagrams (generated using BioVenn2) demonstrating the crossover between headache and anosmia. grey circles demonstrate the denominator (all respondents). Percentages in white show the proportion of the overall group of respondents reporting both symptoms in each Venn. (C) Respondents reporting anosmia ( $n=91$, $41.1 \%$ ) were asked the day of onset and duration of this symptom. The majority of respondents developed anosmia early in illness (median day 3, SD 1.96) and had resolution of anosmia within 2 weeks of its onset $(n=75,84 \%)$.

We were concerned to find that HCWs fell ill at a high rate and at times for a prolonged period in this cohort. In this previously fit and well group of HCWs, a worrying proportion had shortness of breath on minimal exertion and at rest $(31 / 236)$ and $27.5 \%$ had chest pain. Furthermore, a significant minority remained unwell beyond 8 days and many have protracted illnesses beyond this. Prolonged symptoms were not predicted by age or sex, demonstrating the unpredictable nature of COVID-19 in even a generally young, fit and healthy cohort. Protection of HCWs from COVID-19 infection should therefore be a priority to prevent the significant morbidity demonstrated by these findings.

A further point of concern raised by this study is that a significant proportion of HCWs did not seek formal medical advice or assessment despite significant red flag symptoms of shortness of breath or chest pain, and in some cases despite even measured hypoxia at home. Consideration needs to be given as to how best to support patients isolating at home with this level of symptoms (using interventions such as telephone clinics and home oxygen saturation probes) to prevent risk of deterioration and mortality in this population.

This study adds to the literature around COVID-19 symptoms which should trigger self-isolation and diagnostic testing. In our study, there was a significant proportion of this cohort reporting anosmia-41.5\%. This data supports the update to the PHE guidance including anosmia in the case definition. ${ }^{5}$ alongside several other studies collaborating these findings. ${ }^{14}$

There are several limitations of this study which are acknowledged by the authors.

The major limitation to this study was the lack of access to diagnostic swabs during staff illness, and inclusion was based on clinical criteria alone. This could potentially bias the study by including respondents with more mild respiratory viral infections. However, it is worth noting first that the staff illness peak was temporally in keeping with the COVID-19 outbreak across London. Furthermore, data from the SAFER study, a swabbing and sero-prevalence study at the same hospital site, found very high rates of positive SARS-CoV2 PCR positivity and seroconversion rates during the study period. Specifically, within the hospital at which our study was based, $20 \%$ of frontline staff were already seropositive at the end of March when our survey opened; rising to $45 \%$ seropositivity by the end of April 2020. ${ }^{2}$ It is therefore felt highly likely that significant numbers of staff included in this survey would have illness caused by COVID-19.

The second limitation of the study was the possibility that the use of a voluntary online survey to collect data has several sources of bias. It is unlikely that every selfisolating HCW was captured by this approach and we suspect that our sample over-represents the number of training grade doctors in our sample given that $33.9 \%$ of the survey population were doctors. Overall this may lead to an overrepresentation of those in patient-facing roles, leading to overestimation of infection rates. Conversely it is feasible that reduced participation of other HCWs, such as porters, cleaners and domestics, likely to be at high risk of exposure may bias the study in the opposite way. Further investigation will be required to clarify this important point.

The third potential limitation is the potential for selection bias caused by the requirement for participants to have access to the internet, receive and read email lists, and be well enough to complete the survey. This final point is important as very unwell patients or those who died would be missed by our analysis. Therefore, severe COVID-19 illness in HCW is likely to be under-represented in our sample due to selection bias.

In summary, this study found a worrying proportion of HCWs who were previously fit and well went on to developed significant shortness of breath and chest pain, as well as significant morbidity from prolonged illnesses. There is evidence of late healthcare seeking in these HCWs. We would therefore suggest HCWs are provided with support such as telephone clinics, and access to pulse oximeters to support them during their illness. Furthermore this 
study reinforces the importance of anosmia as a symptom in early course of illness enabling differentiation of COVID-19 from other upper respiratory tract illnesses.

\section{Author affiliations}

${ }^{1}$ COVID-19 Response Team, Department of Infectious Diseases, University College London Hospitals NHS Foundation Trust, Hospital for Tropical Diseases, London, UK ${ }^{2}$ Occupational Health, COVID-19 Response Team, University College London Hospitals NHS Foundation Trust, London, UK

${ }^{3}$ Division of Infection and Immunity, University College London, London, UK

Acknowledgements The authors thank Form Assembly https://www. formassembly.com/ for the generosity in providing the Enterprise Cloud Account to facilitate research during the COVID-19 pandemic.

Collaborators The UCLH COVID-19 Response team includes the clinical and nonclinical staff responding to the ongoing COVID-19 Pandemic as part of University College London Hospitals Foundation Trust. Named authors are members of this team.

Contributors AdW and SAL conceived of the presented idea. AdW, SAL, EK, ZC and LCKB contributed to study design. SAL and JC led on distribution of survey. Data collection and analysis were performed by ADW, SAL, EK, ZC, LCKB, JG, JC and RAL. AdW led writing the initial manuscript draft. SAL and JC led on distribution of survey. AdW, SAL, EK, ZC, LCKB, JG, JC and RAL reviewed, edited and finalised the manuscript, providing critical feedback and changes prior to submission. EK, ZC, LCB and JG are joint second co-authors.

Funding The authors have not declared a specific grant for this research from any funding agency in the public, commercial or not-for-profit sectors.

Competing interests EK was employed in 2018-2019 by the London School of Hygiene of Tropical Medicine undertaking research on attitudes toward maternal vaccination. This research was funded by a grant from GlaxoSmithKline (commercial funder) to support research on maternal vaccination. All other authors have completed the ICMJE uniform disclosure form at www.icmje.org/coi_ disclosure.pdf and declare: no support from any organisation for the submitted work; no financial relationships with any organisations that might have an interest in the submitted work in the previous 3 years; no other relationships or activities that could appear to have influenced the submitted work.

Patient consent for publication Not required.

Provenance and peer review Not commissioned; externally peer reviewed.

Data availability statement Data are available upon reasonable request. Data available on reasonable request, communications to corresponding author angus. dewilton@nhs.net; requests will be responded to within 28 days.

Supplemental material This content has been supplied by the author(s). It has not been vetted by BMJ Publishing Group Limited (BMJ) and may not have been peer-reviewed. Any opinions or recommendations discussed are solely those of the author(s) and are not endorsed by BMJ. BMJ disclaims all liability and responsibility arising from any reliance placed on the content. Where the content includes any translated material, BMJ does not warrant the accuracy and reliability of the translations (including but not limited to local regulations, clinical guidelines, terminology, drug names and drug dosages), and is not responsible for any error and/or omissions arising from translation and adaptation or otherwise.
Open access This is an open access article distributed in accordance with the Creative Commons Attribution Non Commercial (CC BY-NC 4.0) license, which permits others to distribute, remix, adapt, build upon this work non-commercially, and license their derivative works on different terms, provided the original work is properly cited, appropriate credit is given, any changes made indicated, and the use is non-commercial. See: http://creativecommons.org/licenses/by-nc/4.0/.

ORCID iD

Angus de Wilton http://orcid.org/0000-0002-3363-8372

\section{REFERENCES}

1 Public Health England. Guidance on social distancing for everyone in the UK. GOV. UK, 2020. Available: https://www.gov.uk/government/ publications/covid-19-guidance-on-social-distancing-and-forvulnerable-people/guidance-on-social-distancing-for-everyonein-the-uk-and-protecting-older-people-and-vulnerable-adults [Accessed 14 Apr 2020].

2 Houlihan C, Vora N, Byrne T, et al. Pandemic peak SARS-CoV-2 infection and seroconversion rates in London frontline health-care workers, 2020. Available: https://www.thelancet.com/pdfs/journals/ lancet/PIIS0140-6736(20)31484-7.pdf [Accessed 9 Sep 2020].

3 SARS-CoV-2 viral. load and the severity of COVID-19 - CEBM, 2020. Available: https://www.cebm.net/covid-19/sars-cov-2-viral-load-andthe-severity-of-covid-19/ [Accessed 14 Apr 2020].

4 England PH. COVID-19: management of exposed healthcare workers and patients in hospital settings. GOV. UK, 2020. Available: https:// www.gov.uk/government/publications/covid-19-management-ofexposed-healthcare-workers-and-patients-in-hospital-settings/ covid-19-management-of-exposed-healthcare-workers-andpatients-in-hospital-settings [Accessed 14 Apr 2020].

5 England PH. Stay at home: guidance for households with possible coronavirus (COVID-19) infection. GOV. UK, 2020. Available: https:// www.gov.uk/government/publications/covid-19-stay-at-homeguidance/stay-at-home-guidance-for-households-with-possiblecoronavirus-covid-19-infection [Accessed 28 Apr 2020].

6 Guan W-J, Ni Z-Y, Hu Y, et al. Clinical characteristics of coronavirus disease 2019 in China. N Engl J Med 2020;382:1708-20.

7 Han Y-N, Feng Z-W, Sun L-N, et al. A comparative-descriptive analysis of clinical characteristics in 2019-coronavirus-infected children and adults. J Med Virol 2020:1602.

8 Kluytmans M, Buiting A, Pas S, et al. SARS-CoV-2 infection in 86 healthcare workers in two Dutch hospitals in March 2020. Infect Dis 2020.

9 Yifan T, Ying L, Chunhong G, et al. Symptom cluster of ICU nurses treating COVID-19 pneumonia patients in Wuhan, China. J Pain Symptom Manage 2020;60:e48-53.

10 Committee RE. REC UCL, 2020. Available: https://ethics.grad.ucl.ac. uk/exemptions.php [Accessed 6 May 2020].

11 Collazos JCO. Venny 2.1.0, 2020. Available: https://bioinfogp.cnb. csic.es/tools/venny/ [Accessed 28 Apr 2020].

12 Hulsen T, de Vlieg J, Alkema W. BioVenn - a web application for the comparison and visualization of biological lists using areaproportional Venn diagrams. BMC Genomics 2008;9:488.

13 Bénézit F, Le Turnier P, Declerck C, et al. Utility of hyposmia and hypogeusia for the diagnosis of COVID-19. Lancet Infect Dis 2020;20:1014-5.

14 Mao L, Jin H, Wang M, et al. Neurologic manifestations of hospitalized patients with coronavirus disease 2019 in Wuhan, China. JAMA Neurol 2020;77:683. 